\title{
MOTIVAÇÕES PARA A PRODUÇÃO DE MATERIAIS DIDÁTICOS DE BAIXO CUSTO PARA ESTUDANTES COM DEFICIÊNCIA VISUAL
}

Motivation to produce low-cost didactic materials to students with visual impairment

Motivaciones para la producción de materiales didácticos de bajo costo para estudiantes con discapacidades visuales

Received: october $/ 2020$

Accepted: november $/ 2020$

Available online: december/2020

Lisânia Cardoso Tederixe, Mestre em Diversidade e Inclusão, Instituto Benjamin Constant, Brasil.

E-mail: $\underline{\text { lisaniac@bol.com.br }}$

Neuza Rejane Wille Lima, Doutora em Ecologia e Recursos Naturais, Universidade Federal

Fluminense, Brasil. E-mail: rejane_lima@id.uff.br

Resumo: A educação é um processo dinâmico e, assim, espera-se que o professor promova experiências criativas e críticas. Desse modo, o ensinar e aprender não podem ser reduzidos a um saber pronto e indiscutível, principalmente para aqueles que têm impedimentos psíquicos e/ou físicos como o visual. Assim, o objetivo do presente estudo foi realizar uma revisão bibliográfica para identificar quais eram as motivações que desencadearam a criatividade docente ao produzir estratégias e materiais didáticos adaptados para o ensino desses alunos com impedimento visual, utilizando materiais economicamente acessíveis. Esse levantamento foi realizado até 20 março de 2020 nos sites: ERIC, Google Acadêmico, SciELO, Periódicos CAPES e ReasearchGate aplicando dez palavras-chaves. Após considerar cinco critérios de exclusão, foram encontradas 40 publicações. Verificou-se que sete tipos de motivações impulsionaram a 
produção de estratégias e materiais inclusivos para o processo de ensino-aprendizagem de alunos com deficiência visual.

Palavras-chave: Revisão de Literatura, Materiais Didáticos de Baixo Custo, Deficiência Visual.

\begin{abstract}
Education is a dynamic process. Therefore, the teacher is expected to promote creative and critical experiences. Thus, teaching and learning cannot be reduced to a ready and indisputable knowledge, especially for those who have psychic and / or physical impediments such as the visual. The objective of the present study was to carry out a bibliographic review to identify what were the motivations that triggered the creativity of teachers when producing strategies and didactic materials adapted for the teaching of these visually impaired students, using low-cost materials. This survey was conducted until March 20, 2020 on the websites: ERIC, Google Scholar, SciELO, CAPES, and ReasearchGate, applying ten keywords. After considering five exclusion criteria, 40 publications were selected. The motivations that drove the production of inclusive strategies and materials to the teaching-learning process of students with visual impairments totaled seven.
\end{abstract}

Keywords: Literature Review, Low Cost Teaching Materials, Visual Disabilities.

Resumen: La educación es un proceso dinámico y, por lo tanto, se espera que el docente promueva experiencias creativas y críticas. Así, la enseñanza y el aprendizaje no se puede reducir a un conocimiento listo e indiscutible, especialmente para quienes tienen impedimentos psíquicos y / o físicos como el visual. Así, el objetivo del presente estudio fue realizar una revisión bibliográfica para identificar cuáles fueron las motivaciones que desencadenaron la creatividad de los docentes a la hora de producir estrategias y materiales didácticos adaptados para la docencia de estos estudiantes con discapacidad visual, utilizando materiales económicamente accesibles. Esta encuesta se realizó hasta el 20 de marzo de 2020 en los sitios web: revistas ERIC, Google Scholar, SciELO, CAPES y ReasearchGate aplicando diez palabras clave. Después de considerar cinco criterios de exclusión, se encontraron 40 publicaciones. Fue encontrado que siete tipos de motivaciones impulsaron la producción de estrategias y materiales inclusivos para el proceso de enseñanza-aprendizaje de estudiantes con discapacidad visual.

Palabras clave: Revisión de literatura, materiales educativos de bajo costo, discapacidad visual.

\title{
INTRODUÇÃO
}

A realidade escolar mostra que o aprendizado dos alunos está fixado na teoria e pouco na prática. O professor como transmissor de conhecimento e o aluno na posição de receptor passivo. Entretanto, segundo Paulo Freire (1921-1997), a educação é um processo dinâmico e, assim sendo, espera-se que o professor promova experiências criativas e críticas, nas quais ensinar e aprender não podem ser reduzidos a um saber pronto e indiscutível (SPOSITO, 2018).

Segundo Martínez (2006),

[...] a utilização da expressão criatividade no trabalho pedagógico [Grifo no original] pode favorecer a complexidade desse processo, no qual não participa apenas a subjetividade individual do professor, mas também, elementos da 
subjetividade social de diferentes espaços sociais tal como se manifestam na subjetividade social do espaço escolar (MARTÍNEZ, 2006, p. 70).

A educação inclusiva visa possibilitar o acesso das pessoas com deficiência e/ou altas habilidades ou superdotação dentro de uma classe regular de ensino. Para tanto, a integração é um fator imprescindível para o desenvolvimento humano (NUEMBERG, 2008), fazendo-se necessário a adaptação de materiais didáticos que preservem tanto o conteúdo programático como as diferenças dos indivíduos que compõem o grupo focal. Destaca-se também a importância dos recursos didáticos como aliados no ensino e aprendizagem de alunos com impedimentos visuais, por exemplo, na escola, pois eles complementam e solidificam os materiais adaptados.

Conforme alertam Santos e Brito (2014),

[...] sendo professor de escola pública sabemos que professor do ensino básico tem pouco tempo para ser um professor/pesquisador, pois sua carga horária excessiva e os diversos problemas estruturais da educação inviabilizam os processos reflexivos e o aprofundamento teórico necessário à prática de pesquisa (SANTOS; BRITO, 2014; p. 1).

$\mathrm{Na}$ atual realidade escolar, se depara com a presença de alunos com diferentes necessidades específicas, como a deficiência visual, auditiva, e a deficiência física e a intelectual. Essa é uma realidade que ocorre em muitas escolas não especializadas, diferentemente da realidade vivida no Instituto Benjamin Constant (IBC), Rio de Janeiro, RJ, que educa e orienta alunos e pessoas com diferentes graus de deficiência visual (cegueira congênita, cegueira adquirida, baixa visão) (PINHO, 2016; DUARTE, 2017; SOUZA, 2019; TEREDRIXE, 2019).

Com a finalidade de assegurar uma educação igualitária e de qualidade é necessário conhecer "estratégias e recursos de ensino que promovam o acesso ao conteúdo de forma a facilitar a compreensão do aluno com deficiência visual, como o uso de materiais didáticos adaptados" (PEDROSA; GUIMARÃES, 2016, p. 1). 


\section{RECURSOS PARA O APRENDIZADO DE ALUNOS COM DEFICIÊNCIA VISUAL}

O processo educacional do aluno com deficiência visual implica na adoção de alguns recursos específicos na área da deficiência visual, colaborando na prática de ensino em seu desenvolvimento social e na aprendizagem de conhecimento geral.

$\mathrm{Na}$ informática, por exemplo, recursos da Tecnologia Assistiva, em hardware (equipamentos) e software (programas) ajudam o educando cego a realizar tarefas escolares. O uso de leitores de tela - Dosvox, NVDA, Virtual Vision, Jaws - possibilita que o aluno tenha maior autonomia e acessibilidade à informação no conteúdo do material digitalizado (DUARTE; LIMA, 2016; PERDIGÃO; LIMA, 2016; PINHO et al., 2016a, 2016b, 2017a, 2017b; DUARTE et al., 2020).

O aluno cego vem utilizando alguns tipos de recursos para escrita na matemática e na informática. Na escrita faz-se necessário o uso da Reglete e ou máquina Perkins, assim o educando cego alfabetiza-se através do sistema Braille. As operações de cálculo matemático são realizadas com o Sorobã (BERNARDO, 2016; PINHO, 2016; PINHO et al., 2016a, 2016b; PINHO et al., 2017a, 2017b; DUARTE et al., 2020).

A escrita em Braille ocorre por três modos distintos: com a reglete, com o punção com a máquina de datilografia Perkins ou com a impressora em Braille. Para a escrita em Braille, os recursos mais utilizados e economicamente acessíveis são a reglete e o punção (DALLABRIDA; LUNARDI, 2008; PINHO, 2016).

A Reglete pode ser usada acoplada a uma prancha ou não. A primeira é chamada de reglete de mesa e a segunda de reglete de bolso. Esta última consiste em uma régua composta por duas partes: aquela que fica no lado superior da folha tem "selas guias" - formadas pelos seis pontos do sistema Braille, em cada sela cabe somente uma letra - e aquela que fica na parte inferior para 
segurar a folha colocado no meio dessas duas partes (DALLABRIDA; LUNARDI, 2008; PINHO, 2016).

O punção é um sistema mais simples por ser um instrumento que serve como um lápis que possibilita fazer as letras em relevo (DALLABRIDA; LUNARDI, 2008; PINHO, 2016). O ábaco (que significa tábua de cálculos em grego) é chamado de soroban pelos japoneses, é um antigo instrumento de cálculo em sistema decimal que estima-se ter surgido na Mesopotâmia há mais de 5500 anos antes de Cristo (OLIVEIRA et al., 2016; PINHO, 2016; COSTA; CERQUEIRA, 2019).

O soroban que foi introduzido no Brasil em 1908, por imigrantes japoneses, (PINHO, 2016; COSTA; CERQUEIRA, 2019). Esse instrumento é indicado para apoiar o ensino da matemática para alunos com deficiência visual por ser um recurso perceptível tátil, portátil, de fácil manejo, além de ser de baixo custo. Ele permite que o aluno estudante aprenda concretamente, os fundamentos da matemática, e consiga realizar qualquer tipo de cálculo, tais como adição, subtração, multiplicação, divisão, raiz quadrada e outros. A parte mais interessante no uso do soroban é o desenvolvimento da técnica para se fazer cálculos mentais (OLIVEIRA et al., 2016).

Para o aluno com baixa visão o educador se apoia em recursos óticos e não óticos que o auxiliarão no aprendizado escolar, tais como os óculos especiais com lente de aumento ou as lupas para ampliar a fonte. Também existem os recursos não ópticos, tais como o contraste das imagens e cores, réguas de aumento, adequação das carteiras em sala de aula, ampliação das fontes e imagens dos livros (BERNARDO, 2016; PINHO et al., 2016a, 2016b; 2017a, 2017b; DUARTE et al., 2020).

Além de tudo isso, ainda existem os de acessórios especiais, tais como lápis 4B ou $6 \mathrm{~B}$ e cadernos com pautas espaçadas e pretas. Finalizando os exemplos, existem na informática telas de monitores com fontes ampliadas (SÁ et al., 2007). 
Assim, segundo as dissertações de Pinho (2016), Souza (2019) e Teredrixe, (2019) na confecção dos materiais didáticos, é imprescindível que as imagens possuam estímulos visuais e táteis que contemplem as diferentes condições de deficiências visuais - cegueira e baixa visão. Isto é, o material adaptado deverá ter elementos tais como:

a) cores contrastantes,

b) textos com fontes ampliadas para baixa visão,

c) escrita em Braille,

d) variados tipos de textura, espessuras (bidimensional ou tridimensional),

e) ser agradável ao tato e

f) possuir tamanhos (ou escalas) adequados para que sejam significativos ao entendimento do aluno.

Com relação à fidelidade "o material deve ter sua representação tão exata quanto possível do modelo original" (CERQUEIRA; FERREIRA, 2000, p. 26), para aproximar ou referendar o quanto possível o modelo à realidade (SOUZA et al., 2019; TEREDRIXE, 2019; SOUZA et al., 2020).

De acordo com Pontes e Fernandes (2018), os recursos didáticos e as tiflotecnologias conjunto de conhecimentos, técnicas e recursos destinados a auxiliar as pessoas com limitação visual a utilizar corretamente as tecnologias, favorecendo assim a autonomia pessoal e a plena integração - são facilitadores no processo de ensino e aprendizado do aluno com deficiência visual, pois esses recursos possibilitam uma educação com qualidade. Desse modo, o aluno exerce o direito de ter sua própria autonomia e independência na sua vida cotidiana e socialmente (SOUZA et al., 2019; SOUZA et al., 2020).

\section{CRIATIVIDADE DOCENTE}


Todos os seres possuem um potencial criativo. Algumas pessoas conseguem se manifestar com mais prontidão e outras ainda se encontram adormecidas. Ser criativo significa flexibilizar o pensamento, é aquele que sai da zona de conforto e se permite novos desafios (TEREDRIXE, 2019). A criatividade, normalmente, acontece em situações inesperadas, um momento de luz, após incessantes buscas para solucionar algum problema (ALENCAR; FLEITCH, 2003).

A motivação para a criatividade docente concentra-se em três fatores: capacitação, aplicação e ambiente (MACHADO, 2005). A capacitação docente contribui para que o professor aprenda técnicas e desenvolva habilidades criativas dentro de sua área de formação, melhorando sua didática de ensino e a qualidade da aula com os seus alunos (SOUZA et al., 2019; 2020).

Hoje, existe um grande interesse por parte da educação com ênfase especial na educação inclusiva que se preocupa com o uso da inteligência emocional e da criatividade como elementos fundamentais para o desenvolvimento pessoal e social, visando incentivar um maior envolvimento dos indivíduos numa sociedade embasada na experimentação e no desenvolvimento da criatividade (RASLAN FILHO; BARROS, 2018).

Considerando as palavras de Sternberg (2006), ao usar a criatividade o aluno pode fazer as suas próprias escolhas. A criatividade não é um dom simplesmente, mas sim uma decisão pessoal de viver algo, de experimentar (RIBEIRO; MORAES, 2014).

Como um fenômeno polissêmico, multidimensional e de acepção plural, a criatividade esconde-se um cenário implícito que não é percebido ou reconhecido por: fatores, definições, conceitos, hipótese e teorias que podem influenciar uma série de sequências de equívocos didáticos e conteudista em suas aplicações nos mais diferentes ângulos, tendo em vista que, por muitas vezes, essas definições transparecem como contraditórias (TORRE, 2005).

Alencar e Fleitch (2003) explicam o processo criativo como um efeito de iluminação que pode se manifestar por uma ideia ou solução que acontece de forma instantânea e não esperada. Do 
mesmo modo, Torre (2005) considera que as pessoas são criativas não por competências genéticas, mas pela capacidade que detém em interagir com o meio social. O sujeito passa por transformações construtivas a partir de fatores intrínsecos ou extrínsecos em um processo de tensão até chegar ao produto. Novamente, Torre (2005) esclarece que a criatividade deveria ser vista como um bem cultural e social, porém, muitas vezes ela é negligenciada dentro do contexto educacional.

Portanto, questiona-se qual seria a imagem de um docente criativo? Seria de um professor de entretenimento que cria músicas com rimas de fórmulas para que os alunos não se esqueçam da química? ou aquele professor com a missão de solucionar todos os percalços de uma educação conservadora excludente com suas práticas pedagógicas limitadas? A resposta esperada é que o professor criativo é aquele que faz uso de várias estratégias didáticas com a finalidade de motivar o aluno à curiosidade de aprender, pois ele precisa incentivar a autonomia do aluno na busca do conhecimento (TORRE, 2005).

A partir do momento em que o professor compreende as necessidades do aluno com deficiência visual, este desenvolve um canal de conexão de suas aulas com aquele com deficiência ou não. Assim, ele supera as influências negativas do ambiente e abre espaço para uma motivação criadora (PINHO et al., 2017a).

A motivação da criatividade docente entra em colapso quando os professores são designados a múltiplas tarefas que exijam tempo, responsabilidades, turmas com excesso de alunos, gerando sentimento de incapacidade. Lubart (2009) sinaliza que a influência do ambiente familiar, da escola e do trabalho pode ocasionar forte impacto na produção criativa do professor - tanto positivo quanto negativo.

Segundo Moreira (2018, p. 147),

A motivação no trabalho tem sido alvo de estudos e pesquisas de teóricos das mais variadas correntes ao longo do século XX. Entender o que motiva e o que satisfaz o trabalhador é descobrir o procedimento a ser adotado com relação a ele, para que melhore seu desempenho profissional, seu entusiasmo, sua vontade de atingir 
determinados objetivos, proporcionando por consequência um melhor desempenho organizacional.

Segundo o Ministério da Educação, a motivação para ensinar alunos com deficiências deve envolver estratégias e táticas criativas para produção de materiais e práticas inclusivas devem ter como base:

no reconhecimento da diversidade existente na população escolar e na necessidade de respeitar e atender a essa diversidade, como estratégias e critérios de atuação docente; e admite decisões que oportunizam adequar a educação escolar às maneiras peculiares de os alunos aprenderem, considerando que o processo de ensino-aprendizagem pressupõe atender à diversificação de necessidades dos alunos na escola (MEC, 2003, p. 22).

\section{AS TEORIAS MOTIVACIONAIS}

Por definição, motivação é "algo que impulsiona uma pessoa a atuar de uma certa maneira" (LOBOS, 1975, p. 17). Assim, identificar a verdadeira motivação das ações representa confirmar a direção e a persistência destas (LOBOS, 1975). Relacionar a motivação de uma determinada conduta com os objetivos por ela perseguidos é pertinente quando se aborda o ensino inclusivo (MEC, 2003).

Segundo Herzberg (1997, p. 75), “a motivação é uma função do crescimento a partir da obtenção de recompensas intrínsecas por um trabalho interessante e desafiador". Destaca-se que Herzberg propôs essa teoria no ambiente do trabalho, porém, neste estudo está sendo adaptada ao ambiente acadêmico para identificar esses fatores na vida dos discentes. A motivação significa que todo comportamento sempre tem uma causa (MAXIMIANO, 2000).

A Teoria dos Dois Fatores de Herzberg (FREDERICK IRVING HERZBERG, 1923 2000), a mais antiga das teorias motivacionais considera que a motivação é resultante de comportamentos que sempre estão relacionados a determinadas causas que podem ser classificados em intrínsecos ou motivacionais e em extrínsecos ou de higiene (LOBOS, 1975; MAXIMIANO, 
2000). A teoria da motivação no ambiente externo e no trabalho depende de dois fatores: higiênicos e motivacionais (CHIAVENATO, 2003).

Herzberg (2000) fundamenta sua teoria que a motivação depende de dois fatores: os motivacionais propriamente ditos (intrínsecos) e os higiênicos (extrínsecos ou ambientais). Os Fatores Motivacionais, ou seja, os fatores intrínsecos estão relacionados com o cargo em si, com os deveres e as tarefas executadas da melhor forma possível que causam uma satisfação elevada e permanente (WERLANG et al., 2015). Tais fatores propiciam o aumento da produtividade em níveis que estão sempre acima da média, envolvendo sentimentos de realização, crescimento profissional e reconhecimento (HERZBERG, 2000).

Os fatores higiênicos são fatores extrínsecos ou ambientais que são relacionados ao ambiente de trabalho, tais como: ambientais da empresa, benefícios salariais, clima organizacional, condições diretrizes estabelecidas, oportunidades, tipos de supervisão, entre outros. O termo higiene reporta a um caráter preventivo para evitar fontes de insatisfação do ambiente (CHIAVENATO, 2003).

Os fatores motivacionais são fatores intrínsecos que estão relacionados com o cargo em si, ou seja, com os deveres e as tarefas a serem executadas (WERLANG et al., 2015). Tais fatores devem causar níveis de satisfação que sejam elevados e duradouros e, assim, aumenta a produtividade em níveis acima do esperado, envolvendo sentimentos de crescimento e reconhecimento profissional e resultados que atendam ou ultrapassem as expectativas de todos (CHIAVENATO, 2003).

\section{INCLUSÃO DOS ALUNOS COM DEFICIÊNCIA}

Dados do censo escolar indicam que há um crescimento na matrícula de alunos com deficiência nas escolas públicas regulares, demandando práticas de ensino inclusivas (MEC, 2003). 
Paralelamente, o censo também registrou um aumento de professores com formação em Educação Especial (BRASIL, 2015a). Porém, muitas das escolas regulares ainda não estão preparadas para receber esse público devido a questões de falta de estrutura física ou de dificuldade em conviver com diversidade de deficiências visuais que podem ser contornadas (SOUZA et al., 2019; TEREDRIXE, 2019; SOUZA et al., 2020). A inclusão favorece que as escolas tenham turmas heterogêneas compostas por educandos com ou sem deficiência (CAMARGO; NARDI, 2008; CAMARGO et al., 2008).

O professor precisa ativar o pensamento criativo a fim de elaborar novas estratégias de ensino apoiadas em materiais didáticos especializados para esse público (PINHO, 2016). Tais materiais devem viabilizar as informações para a compreensão do conteúdo e que possam ser utilizados por todos os alunos da turma (SPOSITO, 2018).

Segundo a Declaração de Salamanca “[...] o termo 'necessidades educacionais especiais' refere-se a todas aquelas crianças ou jovens cujas necessidades educacionais especiais se originam em função de deficiências ou dificuldades de aprendizagem” (UNESCO, 1994, n. p.).

A Lei Brasileira de Inclusão (BRASIL, 2015b), no artigo 27, assegura o direito à educação da pessoa com deficiência:

A educação constitui direito da pessoa com deficiência, assegurando um sistema educacional inclusivo em todos os níveis e aprendizado ao longo de toda a vida, de forma a alcançar o máximo desenvolvimento possível de seus talentos e habilidades físicas, sensoriais, intelectuais e sociais, segundo suas características, interesses e necessidades de aprendizagem.

Porém, o tipo de modelo pedagógico adotado pela escola pode influenciar nas ações do professor. O Ensino Tradicional ainda vigente nas Escolas tradicionais com métodos de ensinos engessados não desperta o professor para cenários criativos, sendo até mesmo inibidoras do potencial criativo (MACHADO, 2005). Isso porque no Ensino Tradicional ainda vigente em muitos 
países, atua de uma forma mecânica, através de métodos engessados e generalizados que desrespeitam as particularidades de cada um (GÔNGORA, 1985).

Nesse cenário, o professor é o sujeito ativo e o aluno o sujeito passivo que deve apenas receber o conhecimento e por si só desenvolver as suas próprias características humanas, políticas e sociais, "nadando contra uma correnteza" através de processos que envolvem a seleção e o favorecimento dos mais aptos (GÔNGORA, 1985). Assim, segundo esse autor,

O caminho cultural em direção ao saber é o mesmo para todos os alunos, desde que se esforcem. Assim, os menos capazes devem lutar para superar as dificuldades e conquistar um lugar junto aos mais capazes. Caso não consigam, devem procurar um ensino mais profissionalizante (GÔNGORA. 1985, p. 23).

Obviamente, se o Ensino Tradicional e a sociedade atuam como "bloqueadores" no desenvolvimento da criatividade de crianças ditas "sem deficiências" ele atua com maior poder de limitação no crescimento cognitivo de crianças com necessidades especiais e, principalmente e infelizmente, naquelas com altas habilidades ou superdotação (ROSAS, 1992).

\section{MATERIAIS DIDÁTICOS ADAPTADOS}

O Ministério da Educação (MEC) é responsável em promover a acessibilidade dos materiais didáticos destinados aos estudantes e aos professores com deficiência (BRASIL, 2017). Porém, no dia a dia, o professor se depara com a necessidade de produzir materiais adaptados para atender conteúdos e demandas que nem sempre foram previstas (PINHO, 2016). O material adaptado deve ser adequado para todos os alunos da turma, com ou sem deficiência, para que não haja diferenças no conteúdo (CAMARGO et al., 2008).

Bandeira (2009) define os materiais didáticos como produtos pedagógicos utilizados na educação como suportes na função de materializar o conteúdo. Os materiais didáticos 
especializados são adaptados ou criados por uma equipe técnica da escola ou por professores que desenvolvem materiais para uso nas em suas aulas com aqueles que apresentam necessidades educacionais especiais.

A proposta da produção desses materiais baseia-se em favorecer de forma concreta, significativa e econômica o ensino de alunos com deficiência visual. Consecutivamente, o atendimento desses alunos apresentará uma melhora no processo de aprendizagem, tornando-os mais participativos e em igualdade de condições com os outros alunos sem deficiência. Os autores Cerqueira e Ferreira (2000, p. 24) avaliam que "talvez em nenhuma outra forma de educação os recursos didáticos assumam tanta importância como na Educação Especial de pessoas deficientes”.

O professor, ao adaptar ou criar material especializado para o ensino de alunos com impedimento visual (cegos ou com baixa visão) deve possibilitar ao aluno a vivência e a experimentação do conteúdo. Do mesmo modo, é preciso que esse aluno faça parte do processo de construção dos materiais, pois, segundo Passos (2012) os materiais devem servir de suporte experimental durante o processo de ensino e aprendizagem e exercer a função de mediadores para facilitar a relação professor-aluno-conhecimento.

Nesse cenário, o objetivo deste estudo foi realizar uma revisão bibliográfica para identificar quais eram as motivações que desencadearam a criatividade docente ao produzir estratégias e materiais didáticos adaptados para o ensino de alunos com impedimento visual, que fossem construídos com materiais de baixo custo, fácil aquisição e/ou recicláveis, visando subsidiar as práticas docentes em escolar especializadas ou inclusivas que atendam crianças com algum tipo de impedimento visual.

\section{METODOLOGIA}


A pesquisa é de caráter quali/quantitativo e, baseia-se em artigos, resumos, dissertações, teses e livros que relatam as motivações intrínsecas ou extrínsecas do professor em sala de aula diante do aluno com deficiência visual ao confeccionar materiais didáticos com poucos recursos, mas que possam ser representativos e fidedignos ao original.

Foram realizadas buscas de estudos qualitativos que foram encontrados até 20 de março de 2020 em cinco bases de dados (ERIC, Google Acadêmico, Periódicos CAPES, Researchgate e SciELO) a fim de responder a seguinte pergunta: "Que tipos de fatores extrínsecos motivaram o docente na produção de materiais adaptados para alunos com deficiência visual?” e, assim, responder quais são os tipos de artifícios que impulsionaram a criatividade docente ao confeccionar materiais com poucos recursos.

Foi realizada uma busca através de operadores booleanos, utilizando-se os termos "e", "ou" conjuntamente com as dez palavras-chave: (1) "material didático alternativo", (2) "material de baixo custo", (3) "deficiência visual", (4) "cego", (5) "baixa visão", (6) "materiais didáticos acessíveis", (7) "materiais para cego", (8) "materiais para deficientes visuais", (9) "ensino de cegos", (10) "ensino de deficientes visuais.

O termo "com deficiência visual" também foi empregado no lugar do antigo termo que era usado pelos autores (deficientes visuais), atendendo a legislação vigente (BRASIL, 2010). Durante essa pesquisa, as palavras-chave foram empregadas nas versões em português, em inglês e em espanhol.

Para Saks (2005),

A busca booleana possibilita a localização de sites e páginas que contêm determinados assuntos ou abordam determinados aspectos de um assunto. Faz com que o site seja localizado, da maneira mais fácil, pelo usuário-consulente-internauta ou pelo consumidor de um determinado produto divulgado na Internet. (SAKS, 2005, p. 5). 
Desse modo, visando atingir os objetivos do estudo, foram seguidas as cinco etapas básicas:

1) busca e seleção das principais fontes disponíveis sobre tópicos referentes à busca booleana; 2) análise sistemática dos conteúdos levantados; 3) listagem dos principais aspectos sobre o tema; 4) verificação da abordagem dos tópicos nas fontes escolhidas; 5) consolidação e sistematização do conhecimento obtido. (SAKS, 2005, p. 7).

\section{RESULTADOS E DISCUSSÃO}

$\mathrm{Na}$ pesquisa bibliográfica foram, inicialmente, encontradas e analisadas 51 publicações científicas, referentes à produção de material didático de baixo custo e/ou reciclado, adaptado, ou seja, economicamente viáveis aos professores da rede de ensino básico, para alunos cegos e com baixa visão, que atenderam aos critérios de inclusão estabelecidos previamente (Tabela 1).

$\mathrm{Na}$ sequência, foram selecionadas as publicações a partir da leitura dos títulos, resumos e metodologia aplicada com base nos seguintes critérios: (1) uso da criatividade no ensino de alunos com deficiência visual e (2) desenvolvimento de adaptações de materiais didáticos para alunos com deficiência visual, confeccionado com insumos de baixo custo/alternativos e ou recicláveis.

Para critérios de exclusão foram descartadas:

(i) as publicações nas quais os materiais não foram aplicados com alunos com deficiência visual e que não atendem aos critérios de materiais didáticos de baixo custo e ou recicláveis e/ou

(ii) não foram confeccionados pelo próprio professor, como recurso de ensino do conteúdo ao aluno cego e com baixa visão, como também as publicações duplicadas. Após aplicado os critérios de exclusões (Tabela 2), 40 publicações compuseram a seleção que foi analisada, contextualmente, com base em sete fatores extrínsecos (Tabela 3) e numericamente (Tabelas 4 e 5). 
Tabela 1 - Busca de pesquisa primária.

\begin{tabular}{|c|c|}
\hline Base de Dados & Estudo Qualitativo Encontrado \\
\hline - $\quad$ ERIC & 12 \\
\hline - $\quad$ Google Acadêmico & 20 \\
\hline - $\quad$ Periódicos Capes & 02 \\
\hline $\begin{array}{ll} & \text { Research Gate }\end{array}$ & 04 \\
\hline - $\quad$ SciELO & 13 \\
\hline - TOTAL & 51 \\
\hline
\end{tabular}

Fonte: Elaborado pelos autores.

Tabela 2 - Critérios de exclusão aplicados para realizar a seleção das publicações

\begin{tabular}{l|c}
\hline Critério & Quantidades \\
\hline Duplicadas. & 7 \\
\hline $\begin{array}{l}\text { Material de baixo custo utilizado como recurso didático, mas não testado com } \\
\text { alunos com deficiência visual. }\end{array}$ & 7 \\
\hline$-\quad$ Material de baixo custo não utilizado como recurso didático. & 3 \\
\hline $\begin{array}{l}\text { Material de custo relativamente alto ou de difícil aquisição utilizado como recurso } \\
\text { didático. }\end{array}$ & 1 \\
\hline
\end{tabular}

Fonte: Elaborado pelos autores.

Tabela 3: Fatores intrínsecos identificados como aqueles relevantes para desencadear a motivação do professor para construir os materiais e/ou estratégias para alunos com deficiência visual.

\section{FATORES INTRÍNSECOS}

1. Possibilitar uma Educação Inclusiva de alunos com deficiência visual no sistema regular de ensino.

2. Materiais pedagógicos adaptados de fácil confecção com sucatas e ou objetos baratos para serem utilizados em sala de aula, devido à escassez de material apropriado no mercado para o ensino e aprendizado do aluno com deficiência visual.

3. Produzir materiais adaptados que possam ser utilizados em conjunto com alunos, sem ou com deficiência visual, na mesma turma.

4. Trabalhar de forma lúdica com os alunos para facilitar o aprendizado.

5. Acessibilizar materiais didáticos.

6. Favorecer a inclusão das informações contidas nas imagens visuais, por meio da reprodução em imagens táteis. 
7. Estimular a criatividade e a curiosidade do aluno.

Fonte: Elaborado pelos autores.

A Tabela 4 tem como função principal auxiliar na apresentação e análises dos resultados obtidos, ou seja, as 40 publicações relativas ao objetivo proposto. Nessa tabela constam dados sobre as publicações: título; autor(res); o ano da publicação; objetivos e identificação a qual fator extrínseco foi preponderante para os autores.

A distribuição dos sete tipos de Fatores Intrínsecos entre os 40 artigos encontrados (Tabela 3 e 4) ocorreu de modo, praticamente, homogênea, variando entre 7,5\% e 22,5\% (Figura 1). Verificou-se que o Fator Intrínseco no. 7 foi o menos empregado pelos autores $(7,5 \%$ dos casos) enquanto aquele de no. 6 foi o mais empregado $(22,5 \%$ dos casos $)$.

Tabela 4 - Relação das 40 publicações selecionadas, seus principais objetivos e classificação considerando dentre os sete Fatores Intrínsecos (FI) que estão discriminados na Tabela 2, aquele que melhor explica a motivação dos professores para execução dos materiais didáticos e inclusivos para alunos com deficiência visual (DV).

\begin{tabular}{|c|c|c|}
\hline Publicações / Autores & Proposta do Trabalho & FI \\
\hline $\begin{array}{l}\text { 1. O estudo da geometria. (BARBOSA, } \\
\text { 2003). }\end{array}$ & $\begin{array}{l}\text { - Indicar uma metodologia para auxiliar o processo } \\
\text { de aprendizagem dos alunos com DV. }\end{array}$ & 7 \\
\hline $\begin{array}{l}\text { 2. Panorama geral das dificuldades e } \\
\text { viabilidades para a inclusão do aluno } \\
\text { com deficiência visual em aulas de } \\
\text { eletromagnetismo. } \\
\text { NARDI, 2008). }\end{array}$ & $\begin{array}{l}\text { - Compreender quais são as principais barreiras e } \\
\text { alternativas para a inclusão de alunos com DV } \\
\text { contexto do ensino de física. }\end{array}$ & 1 \\
\hline $\begin{array}{l}\text { 3. A comunicação como barreira à } \\
\text { inclusão de alunos com deficiência } \\
\text { visual em aulas de óptica. (CAMARGO } \\
\text { et al., 2008). }\end{array}$ & $\begin{array}{l}\text { - Em continuação do artigo (2) esse artigo também } \\
\text { visou compreender as principais barreiras para a } \\
\text { inclusão de alunos com DV no contexto do ensino } \\
\text { de física }\end{array}$ & 1 \\
\hline $\begin{array}{l}\text { 4.Atividades de observação } \mathrm{e} \\
\text { identificação do céu adaptadas às } \\
\text { pessoas com deficiência visual. } \\
\text { (DOMINICI et al., 2008). }\end{array}$ & $\begin{array}{l}\text { - Ensino prático da Astronomia para o público DV, } \\
\text { oferecendo soluções através do desenvolvimento de } \\
\text { material didático (kit) criado exclusivamente para } \\
\text { este fim. }\end{array}$ & 3 \\
\hline $\begin{array}{l}\text { 5. Materiais pedagógicos de baixo custo } \\
\text { para o ensino de corrente elétrica para } \\
\text { alunos com deficiência visual. } \\
\text { (EVANGELISTA, 2008). }\end{array}$ & $\begin{array}{l}\text { - Produzir materiais pedagógicos de baixo custo } \\
\text { para o ensino de corrente elétrica para alunos com } \\
\text { DV. }\end{array}$ & 3 \\
\hline $\begin{array}{l}\text { 6. Adaptações laboratoriais de baixo } \\
\text { custo para estudantes pré-universitários } \\
\text { cegos ou deficientes visuais. } \\
\text { (GRAYBILL et al., 2008). }\end{array}$ & $\begin{array}{l}\text { - Aplicação criativa de materiais e técnicas de baixo } \\
\text { custo disponíveis para promover a inclusão e } \\
\text { fornece acessibilidade na sala de aula e no } \\
\text { laboratório para alunos com DV. }\end{array}$ & 6 \\
\hline
\end{tabular}


7. Produção e adaptação de material didático para apoiar aluno deficiente visual no ensino da computação em curso de graduação na modalidade EAD. (ANDRADE; FERNANDES, 2013).

8. Software XLUPA - um amplificador de tela para auxílio na educação de alunos com baixa visão. (BIDARRA et al., 2011).

9. Produção de material didático para alunos com deficiência visual. (BONADIMAN, 2011).
- Processo de produção, adaptação e análises de material de didático para apoiar o ensino da computação em curso de graduação na modalidade EAD a aluno com DV.

- Descrição da especificação e desenvolvimento da ferramenta, o que envolveu um estudo das necessidades do aluno com DV, bem como a interação contínua de desenvolvedores e usuários; do software x Lupa e de suas funcionalidades.

- Projeto-piloto implementado - com sucesso- no Consórcio CEDERJ, tendo como objetivo apresentar uma técnica de produção de material didático que atenda às necessidades de alunos com DV.

\section{Robótica educativa/pedagógica}

na era digital. (D'ABREU et al., 2012).

- Aborda a Robótica Educativa sob a ótica de desenvolvimento de atividades, na sala aula, utilizando computadores e material alternativo de baixo custo.

11. Inclusão de estudantes cegos nas aulas de matemática: a construção de um kit pedagógico. (ULIANA, 2013).
- Criação, confecção e experimentação de um kit de material pedagógico composto de uma placa de metal com manta magnética quadriculada em uma das faces, eixos x e y de ímã com numeração em Braille, formas geométricas planas em EVA. O kit possibilita que, através do sentido do tato, o aprendiz cego realize diversas atividades matemáticas.

- Ajudar os alunos deficientes visuais a representar e dar significado ao mundo por meio das relações entre os modelos geométricos criados e/ou manipulados, possibilitando a compreensão de representações abstratas. Possibilitar ao aluno o reconhecimento de um ângulo e suas aplicações no dia a dia.

- Elaboração de materiais e métodos auxiliares para a formação dos conceitos através do tato que constitui um recurso importante, bem como a ideia de representação dos conceitos no processo de aprendizagem.

- Mapeamento digital para Braille de diagramas de geometria na impressora de texto Braille tradicional de baixo custo é relatado aqui usando o sistema integrado, um aluno cego pode inserir um problema de palavra de geometria e perceber o diagrama subjacente em uma impressão em Braille.

- Elaboração de materiais adaptados contendo conteúdos de Astronomia que contribuíssem para o aprendizado de alunos com e sem DV. Inovando em materiais didáticos acessíveis. (SOARES et al., 2015) 


\begin{tabular}{|c|c|c|}
\hline $\begin{array}{l}\text { 16. Recursos e adaptação de materiais } \\
\text { didáticos para a inclusão de alunos com } \\
\text { deficiência visual no ensino de } \\
\text { matemática. (BERNARDO, 2016). }\end{array}$ & $\begin{array}{l}\text { - Produção científica relacionada às práticas } \\
\text { pedagógicas que permeiam o cenário de } \\
\text { ensino-aprendizagem no terreiro e que contribuem } \\
\text { para o pleno desenvolvimento do ser, contribuindo } \\
\text { em questões que valorizam o corpo e a vida. }\end{array}$ & 6 \\
\hline $\begin{array}{l}\text { 17. Origami como uma ferramenta para } \\
\text { ensinar geometria para alunos cegos. } \\
\text { (PINHO et al., 2016a). }\end{array}$ & $\begin{array}{l}\text { - Demonstrar demonstrou a eficácia do origami no } \\
\text { ensino de matemática para alunos cegos } \\
\text { adolescentes. }\end{array}$ & 4 \\
\hline $\begin{array}{l}\text { 18. Material manipulável de geometria } \\
\text { para estudantes cegos: reflexões de } \\
\text { professores brailistas. (SILVA et al., } \\
\text { 2016). }\end{array}$ & $\begin{array}{l}\text { - Realizar entrevista semiestruturada com questões } \\
\text { sobre formação inicial e continuada, atribuições e } \\
\text { experiência profissional, uso de material didático } \\
\text { para o ensino de Matemática para alunos cegos e } \\
\text { avaliação de material manipulável destinado ao } \\
\text { ensino de geometria. }\end{array}$ & 6 \\
\hline $\begin{array}{l}\text { 19. Promovendo o ensino inclusivo de } \\
\text { química através do desenvolvimento de } \\
\text { um termômetro acessível para alunos } \\
\text { com deficiências visuais. (VITORIANO } \\
\text { et al., 2016). }\end{array}$ & $\begin{array}{l}\text { - Construir e avaliar um termômetro digital } \\
\text { especialmente projetado para ser operado por } \\
\text { pessoas com DV. }\end{array}$ & 1 \\
\hline $\begin{array}{l}\text { 21. A elaboração de recursos didáticos } \\
\text { para o ensino de Astronomia para } \\
\text { deficientes visuais. (ANDRADE; } \\
\text { IACHEL, 2017). }\end{array}$ & $\begin{array}{l}\text { - Compreender que o ensino de Astronomia deva } \\
\text { considerar e ser adaptado para incluir estudantes } \\
\text { com deficiência visual, para que eles possam } \\
\text { aprender os fenômenos naturais do Universo e } \\
\text { receber estímulo nesta área de estudo. }\end{array}$ & 2 \\
\hline $\begin{array}{l}\text { 22. Ensino de Química para deficientes } \\
\text { visuais numa perspectiva inclusiva: } \\
\text { estudo sobre o ensino da distribuição } \\
\text { eletrônica e identificação dos elementos } \\
\text { químicos. (FARIA et al., 2017). }\end{array}$ & $\begin{array}{l}\text { - Usar a tecnologia assistiva para auxiliar na } \\
\text { localização de elementos na tabela periódica e } \\
\text { distribuição eletrônica permitiu com que os alunos } \\
\text { com DV pudessem, de forma autônoma, identificar } \\
\text { a localização dos elementos e seus símbolos. }\end{array}$ & 5 \\
\hline $\begin{array}{l}\text { 23. A elaboração de materiais para o } \\
\text { ensino de modelos atômicos e } \\
\text { distribuição eletrônica para discente } \\
\text { cego: produtos de um projeto } \\
\text { PROBIC-JR. (FERNANDES et al., } \\
\text { 2017). }\end{array}$ & $\begin{array}{l}\text { - Mostrar e discutir materiais táteis para o ensino de } \\
\text { modelos atômicos e de distribuição eletrônica para } \\
\text { alunos cegos. }\end{array}$ & 6 \\
\hline 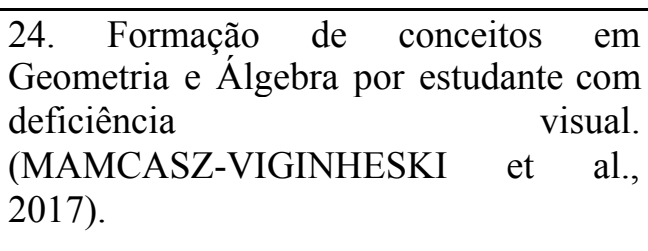 & $\begin{array}{l}\text { - Intervenção pedagógica para que a estudante } \\
\text { elaborasse conceitos de Geometria e Álgebra. }\end{array}$ & 7 \\
\hline $\begin{array}{l}\text { 25. Atividade experimental de química } \\
\text { para uma turma inclusiva com um } \\
\text { estudante cego: a importância do estudo } \\
\text { do contexto. (MARRA et al., 2017). }\end{array}$ & $\begin{array}{l}\text { - Elaborar uma atividade experimental para uma } \\
\text { turma do primeiro ano do ensino médio em que há } \\
\text { um aluno cego. }\end{array}$ & 3 \\
\hline
\end{tabular}


26. Dobraduras e colagens no ensino de geometria para estudantes cegos do ensino fundamental no período de contraturno. (PINHO; LIMA, 2017a).
- Avaliar a eficácia de seis oficinas envolvendo atividades lúdicas com utilização de materiais reaproveitáveis ou de baixo custo para construir objetos e abordar os elementos geométricos do triangulo retângulo, figuras plana e não plana e do círculo, visando promover a construção de conhecimentos sobre conteúdos de matemática em estudantes cegos.
27. O uso da música em uma oficina de geometria para alunos cegos do ensino fundamental. (PINHO; LIMA, 2017b).

28. Matemática inclusiva: ensinando matrizes a deficientes visuais. (SILVA; LAZZARIN, 2017).

- Desenvolvimento e aplicação de estratégia para iniciar o ensino de matemática para estudantes com DV.

- Relatar um processo de ensino-aprendizagem, procurando introduzir o conceito de matrizes e suas operações elementares para um aluno com deficiência visual total utilizando-se de material concreto simples o qual pode ser confeccionado sem grandes recursos.

29. Mapvoice: ferramenta computacional para auxiliar na cartografia de aprendizagem para deficientes visuais. (BARBOSA; SÁ, 2018).

- O objetivo foi habilitar o software MapVoice para estudantes com DV, da educação básica, na aprendizagem de cartografia em aulas de Geografia. Fornece a compreensão e interpretação de ambientes físicos transformados em mapas temáticos com base nos dados do Censo Demográfico Brasileiro de 2010 executado pelo IBGE.

- Planejamento, a elaboração e a testagem de um produto educacional intitulado Lâminas em Alto Relevo para o Ensino de Ondas e Fenômenos Ondulatórios a Deficientes Visuais. visuais. (SILVA; SANTOS, 2018).

31. Livro tátil: um recurso no aprendizado do aluno com deficiência visual. (TEDERIXE; LIMA, 2018).

32. Ensino de biologia celular por meio de modelos concretos: um estudo de caso no contexto da deficiência visual. (COSTA et al., 2019a).

33 Ensino de frações para adolescentes com deficiência visual. (COSTA et al., 2019b).

Verificar a construção e utilização de modelos concretos podem facilitar aprendizagem de conceitos desde a concepção da disciplina, especialmente biologia celular para que o aluno com DV percebesse as diferenças entre um ser vivo e uma matéria-prima e que todos os seres vivos são formados por algum tipo de célula.

- Ensinar frações unitárias e não unitárias para três adolescentes com deficiência visual, empregando tentativas discretas, instruções orais e reforçamento diferencial em um delineamento do tipo A-B com follow up. 
34. Projeto e construção de um sensor de $\mathrm{pH}$ de baixo custo baseado em Arduino para deficientes visuais usando papel de $\mathrm{pH}$ universal. (QUTIESHAT et al., 2019).
- Descrever o projeto e a construção de um sensor de $\mathrm{pH}$ simples baseado em Arduino usando papel de $\mathrm{pH}$ universal para estudantes com DV.
35. Educação inclusiva: modelo didático de peixe para alunos com deficiência visual no ensino de ciências e biologia. (SANTOS; BRITO, 2019).
- Uso de recursos didáticos diferenciados mostra-se um potencial instrumento na aquisição do conhecimento, desmistificando os estigmas relacionados à percepção do aluno cego. A criatividade e o baixo custo na produção tornam-se ferramentas importantes e despertam entusiasmo dos alunos em aprender e dos professores ao ensinar.

- Reconhecer potencialidades e limitações do uso de um material concreto acessível para o ensino de operações com polinômios em uma turma regular com estudantes cegos inseridos. potencialidades e limitações. (DIAS; PANOSSIAN, 2018).
37. Sensibilizando futuros docentes para uma prática pedagógica inclusiva através da construção de um livro tátil: uma reflexão necessária. (SOUZA et al., 2019).

38. Construção de uma maquete do sistema solar com controle de temperatura para alunos com deficiência visual. (ALMEIDA et al., 2020).
- Relatar o processo de sensibilização de universitários para verificar a importância de garantir a inclusão dos alunos com deficiência visual no processo ensino-aprendizagem num cotidiano cujo uso de imagens é preponderante.

- Desenvolvimento de um conjunto didático baseado no uso do tato e de elementos com controle térmico para o ensino de Astronomia diante das dificuldades encontradas na busca de experimentos capazes de apresentar, da melhor forma, conceitos envolvidos no ensino de Astronomia para pessoas com DV.

- Produzir um livro tátil tridimensional com história autoral sobre saúde bucal envolvendo o tema cárie. da saúde bucal de alunos cegos utilizando livro tátil tridimensional. (SOUZA et al., 2020).

40. Identificação de imagens táteis texturizadas em crianças com deficiência visual e olhos vendados. (VINTER et al., 2020).

- Investigaram se crianças cegas de 3 a 8 anos de idade demonstrariam uma habilidade satisfatória para nomear os elementos que compõem as imagens táteis quando testadas em um ambiente experimental semelhante às suas condições naturais de leitura.

Fonte: Elaborado pelos autores. 
Os resultados obtidos apontam que houve uma leve tendência a favorecer o uso de imagens visuais em objetos facilmente apalpáveis como Fator Intrínseco na busca de produzir estratégias de ensino para atendimento de alunos com deficiência visual (Tabela 3 e 4; Figura 1).

Assim, tanto o Fator Intrínseco de no. 1 - como o de no. 3 estavam presentes em 17,5\% dos artigos encontrados (Tabela 3 e 4; Figura 1). Verificou-se que o Fator Intrínseco no. 7 foi o menos empregado pelos autores (7,5\% dos casos), enquanto aquele de no. 6 foi o mais empregado $(22,5 \%$ dos casos).

Isso aponta que houve uma leve tendência a se favorecer a inclusão das informações em imagens táteis como Fator Intrínseco na busca de produzir estratégias de ensino para atendimento de alunos com deficiência visual.

Figura 1- Distribuição percentual (\%) para os sete Fatores Intrínsecos (FI) listados na Tabela 3 que foram relevantes para desencadear a motivação do professor para a construção dos materiais e/ou estratégias para crianças com deficiência visual nos 40 artigos encontrados e listados na Tabela 4.

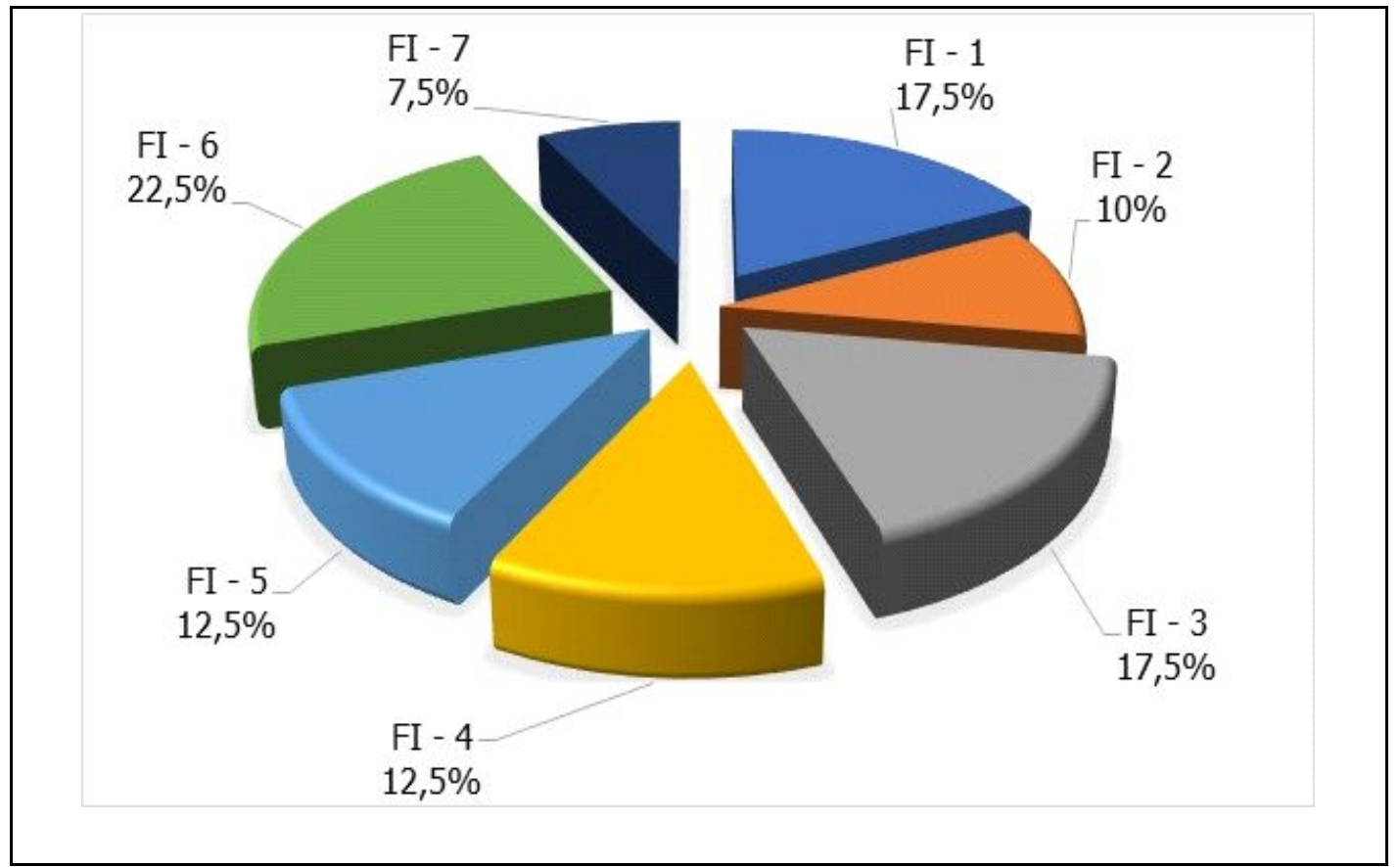

Legenda: FI - 1: Possibilitar uma Educação Inclusiva de alunos com deficiência visual no sistema regular de ensino., FI - 2: Materiais pedagógicos adaptados de fácil confecção com sucatas e ou objetos baratos para serem utilizados em sala de aula, devido à escassez de material apropriado no mercado para o ensino e aprendizado do aluno com deficiência visual., FI - 3: Produzir materiais adaptados que possam ser utilizados em conjunto com alunos, sem ou com deficiência visual, na mesma turma., FI - 4: Trabalhar de forma lúdica com os alunos para facilitar o aprendizado, FI 5: Acessibilizar materiais didáticos., FI - 6: Favorecer a inclusão das informações contidas nas imagens visuais, por meio da reprodução em imagens táteis, FI - 7: Estimular a criatividade e a curiosidade do aluno.). Fonte: Elaborado pelos autores. 


\section{EXEMPLOS DO USO DOS FATORES INTRÍNSECOS}

Vinte dos 40 artigos encontrados (Tabela 3 e 4) foram escolhidos para exemplificar como os sete fatores motivadores identificados estiveram relacionados às estratégias de elaborar e/ou adaptar materiais didáticos direcionados para alunos com deficiência visual, conforme listagem a seguir:

\section{Possibilitar uma Educação Inclusiva de alunos com deficiência visual no sistema} regular de ensino - O artigo publicado por Silva e Lazzarin (2017) descreve sobre a necessidade da construção de matrizes como métodos alternativos para o ensino de Matemática que surgiu a partir da inclusão de alunos com deficiência visual na sala de aula. Fatores extrínsecos motivaram a elaboração do material. Assim como D'Abreu et al. (2012) pontuam que o uso de Robótica Educativa Pedagógica de Baixo Custo com o projeto do mapa tátil contribuiu para que o aluno com deficiência visual tivesse inclusão social e educacional e aos poucos pudesse ingressar na era digital. A confecção do mapa tátil contou com a interação de alunos cegos da escola pública municipal e de usuários que frequentam o campus da Unicamp. Esse mapa possibilitou o deslocamento seguro e a identificação da área geográfica do referido campus.

2. Elaborar materiais pedagógicos adaptados de fácil confecção com sucatas e ou objetos baratos para serem utilizados em sala de aula, devido à escassez de material apropriado no mercado para o ensino e aprendizado do aluno com deficiência visual - $\mathrm{O}$ artigo de Andrade e Iachel (2017) apontou a necessidade de produzir materiais a partir de artefatos mais econômicos, para o ensino de Astronomia. Materiais que facilitassem a compreensão dessa ciência, como também a carência de material concreto destinado a pessoas com deficiência. Os autores apresentaram duas motivações para a confecção do material: poucos recursos didáticos em Astronomia, na Educação Inclusiva de pessoas com deficiência visual e a capacitação docente decorrente da falta de experiência destes no desenvolvimento de material especializado. No artigo publicado por Uliana (2013), a motivação surgiu da necessidade pedagógica de produzir um kit tátil 
que ensinasse a construção e a análise de gráficos de funções polinomiais, de primeiro e segundo graus para um aluno cego que cursava o nono ano.

\section{Produzir materiais adaptados que possam ser utilizados em conjunto com alunos, sem}

ou com deficiência visual, na mesma turma - Dentro de um cenário inclusivo, todos os materiais adaptados devem ser adequados aos dois públicos para que ambos experimentem e aprendam com o material igualmente. Para Evangelista (2008) o ensino e o aprendizado do tabuleiro para ensinar corrente elétrica aos alunos com ou sem deficiência visual no ensino regular não se apresentam de forma adequada visto que os alunos com deficiência visual necessitam da exploração tátil do material em questão. A partir do apontamento de Evangelista (2008) ressalta-se a importância dos estudos minuciosos do melhor tipo de matéria-prima e a necessidade da capacitação docente para a produção de material especializado de baixo custo. Ainda nesse contexto, Abreu (2014) apresentou uma proposta de criar materiais adaptados para o ensino de geometria, mas que possam ser utilizados por todos os públicos: vidente, cegos ou com baixa visão. Isso é importante quando se pensa na inclusão de todos em sala de aula.

4. Trabalhar de forma lúdica com os alunos para facilitar o aprendizado - Apesar desse Fator Extrínseco só ter sido observado em cerca de $12 \%$ dos estudos encontrados na pesquisa (Tabela 4), se verificou que entre estes encontra-se a maior diversidade de estratégias e Soares et al. (2015) esclareceram que a ludicidade nos materiais, como os jogos didáticos de memória dos astros do sistema solar é um meio alternativo e satisfatório uma vez que o jogo despertou o interesse de aprender no aluno. Os estudos de Pinho et al. (2016) e de Pinho e Lima (2017a) apontam a ludicidade como meio relevante para trabalhar conceitos de Matemática por intermédio de dobraduras e colagens construindo objetos com base nas figuras planas geométricas e não planas em conjunto com os alunos, o que seria o aprender-fazendo. As autoras Pinho e Lima (2017b) utilizaram a música para introduzir elementos geométricos em aula de Matemática. Os estudos de Souza et al. (2019) e de Souza et al. (2020) lançaram mão de livros táteis tridimensionais para 
abordar questões como a prevenção contra a catapora e higiene bucal, respectivamente. Nos estudos desenvolvidos por Tederixe e Lima (2019) e, mais detalhadamente, em Tederixe (2019) abordou-se a arte de Wassily Kandinsky através da produção de um livro tátil bidimensional.

5. Acessibilizar materiais didáticos - Todos os artigos apresentaram como proposta a acessibilidade do material didático como método de ensinar conceitos abstratos de modo concreto. Andrade e Fernandes (2013) sinalizam a importância de tornar acessíveis os materiais didáticos digitalizados para os alunos com deficiência visual na modalidade de educação à distância, produzindo material de apoio adaptado e de baixo custo para o ensino de Computação. Faria et al. (2011) assim como Barbosa e Sá (2018), desenvolveram software que contribuíram de forma interdisciplinar no aprendizado dos alunos cegos ou com baixa visão. A tecnologia tem sido uma grande aliada como mais um recurso de ensino. Faria et al. (2017) elucidaram que métodos alternativos com uso de materiais adequados em parceria com as tecnologias assistivas, facilitam na compreensão de conteúdos por alunos com deficiência visual.

\section{Favorecer a inclusão das informações contidas nas imagens visuais, por meio da} reprodução em imagens táteis - O artigo de Azevedo e Santos (2014) evidencia a importância do ciclo de aprendizagem de Karplus que é composto de três fases: exploração, introdução do conceito e aplicação do conceito, a partir do material adaptado em física para alunos com deficiência visual. A motivação do professor estava em melhorar a abordagem da disciplina com os alunos e que eles pudessem aprender, pela exploração tátil, conceitos na Matemática e Física com o material concreto. Segundo Bernardo (2016) a confecção em Matemática de material adaptado tátil deve ser de forma mais significativa e concreta para que o aluno com deficiência visual apreenda o conteúdo. O estudo realizado por Silva e Santos (2018) descreveu a produção de materiais de forma artesanal que pudessem ser significativos na construção de conceitos sobre os tipos de ondas e o fenômeno ondulatório. Esses autores sinalizam que produzir este tipo de material é muito trabalhoso. 
7. Estimular a criatividade e a curiosidade do aluno - De acordo com Barbosa (2003), o professor ao confeccionar e adaptar materiais pedagógicos na Geometria, usando a criatividade, contribuirá para o processo de ensino-aprendizado de todo o tipo de aluno, com ou sem deficiência visual. Como também, a participação do aluno no processo de construção do material é essencial. Barbosa (2003, p. 10) também enfatiza que "a formação de alunos mais criativos exige um papel mais ativo dos alunos e do professor, pois está em jogo o próprio exercício do pensamento”.

Isso demonstra que é possível, com base nesses fatores, produzir ou simplesmente pesquisar sobre o que há de disponível para estimular a criatividade do professor que vê frente ao desafio de estimular a criatividade e a construção do conhecimento de alunos com deficiência visual, pois pessoas cegas ou com baixa visão devem ser educadas de forma construtiva e inclusiva para que eles possam viver plenamente na sociedade de modo salutar em termos emocionais, sociais e profissionais (PINHO et al., 2017b).

Como resultado das políticas públicas vigentes, podemos ver mais pessoas com deficiência visual em nossa sociedade trabalhando e vivendo fora de suas casas como cidadãos. Porém isso só é possível através da oferta de um ensino eficiente e construtivo. Ainda é necessário o desenvolvimento de mais pesquisas, estratégias e a produção de materiais didáticos adaptados como também desenvolver estratégias estimuladoras da criatividade. Assim, é premente que continue a promoção do desenvolvimento de materiais adaptados para oferecer aos alunos com deficiência visual o mesmo nível de qualidade oferecido a todo e qualquer aluno, cumprindo as leis vigentes que garantem a Educação Especial com a perspectiva inclusiva.

\section{CONCLUSÕES}

A construção de materiais adaptados exige pesquisa do docente para que estes sejam significativos e adequados ao uso dos alunos com deficiência visual. É importante ter conhecimento técnico, criatividade e bom senso na fabricação desses materiais especializados ao escolher artefatos 
mais em conta e ao mesmo tempo funcionais e, principalmente, seguros para a exploração tátil. $\mathrm{O}$ ideal é que o material didático inclusivo também seja atrativo para crianças videntes para o caso de uma turma mista quanto às necessidades especiais ou para ser explorado em salas de recursos.

Com base nos resultados relatados e discutidos, o presente estudo mostrou que o processo de inclusão do aluno com deficiência visual nas escolas regulares tem ocorrido através da inclusão das informações contidas nas imagens visuais, por meio da reprodução em imagens táteis. Assim sendo, o Fator Intrínseco de no. 6, ou seja, a reprodução em imagens táteis foi aquela mais frequente dentre as motivações expressadas pelos docentes com vistas a desenvolver material adaptado que pudesse viabilizar, de forma concreta, a exposição de conteúdo programáticos para os alunos com cegueira ou baixa visão e, assim, contribuir na construção autônoma dos seus conhecimentos.

\section{REFERÊNCIAS}

ABREU, Lívia Azelman de Faria. Geometria para deficiente visual: uma proposta de ensino utilizando materiais concretos. Dissertação (Mestrado em Matemática, Centro de Ciências e Tecnologia da Universidade Estadual do Norte Fluminense Darcy Ribeiro), Campos de Goytacazes, RJ, 2014.

ALENCAR, Eunice Maria Lima Soriano de FLEITH, Denise de Souza. Criatividade: múltiplas perspectivas. $3^{\mathrm{a}} \mathrm{ed}$. Brasília: Editora UNB. 2003.

ANDRADE, Cristiano César dos Santos; FERNANDES, Edicléia Mascarenhas. Produção e adaptação de material didático para apoiar o ensino da computação, no curso de graduação na modalidade EAD. Universidade Federal Fluminense, Polo CEDERJ/UAB de Belford, 2013.

ANDRADE, Daniela Pimenta de; IACHEL, Gustavo. A elaboração de recursos didáticos para o ensino de Astronomia para deficientes visuais. In: XI ENCONTRO NACIONAL DE PESQUISA EM EDUCAÇÃO EM CIÊNCIAS. Universidade Federal de Santa Catarina, Florianópolis, SC., Florianópolis, SC. ABRAPECNET, 2017.

AZEVEDO, Alexandre Cesar; SANTOS, Antônio Carlos. F. Ciclos de aprendizagem no ensino de física para deficientes visuais. Revista Brasileira de Ensino de Física, v. 36, n. 4, 2014. DOI: 10.1590/S1806-11172014000400017

BANDEIRA, Denise. Material didático: conceito, classificação geral e aspectos da elaboração. In: CIFFONE, H. (Org.). Curso de Materiais didáticos para smartphone e tablet. Curitiba, IESDE, p. 13-33, 2009. 
BARBOSA, Leonardo Carlos; SÁ, Lucilene Antunes Correia Marques de. Mapvoice: computational tool to aid in learning cartography for the visually impaired. Bulletin of Geodetic Sciences, v. 24, n. 1, 2018. DOI: 10.1590/s1982-21702018000100005

BARBOSA, Paula Marcia. O estudo da geometria. Revista Benjamin Constant, Edição n ${ }^{0} 25$, 2003.

BERNARDO, Fábio Garcia. Recursos e adaptação de materiais didáticos para a inclusão de alunos com deficiência visual no ensino de matemática. Educação Básica, 2016.

BIDARRA, Jorge; BOSCARIOLI, Clodis; PERES, Sarajane Marques. Software X-lupa - um ampliador de tela para auxílio na educação de alunos com baixa visão. Revista Brasileira de Educação Especial, v. 17, n. 1, p. 151-172, 2011.

BONADIMAN, Tereza Cristina Nunes de Queiroz. Produção de material didático para alunos com deficiência visual. Revista Tecnologia e Cultura, Ano 13, n. 18 - p. 61-68, 2011.

BRASIL. Decreto no 9.099 de 18 de julho de 2017. 2017. Dispõe sobre o Programa Nacional do Livro e do Material Didático.

BRASIL. Lei no 13.146, de 6 de julho de 2015. 2015a. Institui a Lei Brasileira de Inclusão da Pessoa com Deficiência (Estatuto da Pessoa com Deficiência), 2015a.

BRASIL. Ministério da Educação. Dados do Censo Escolar indicam aumento de matrícula de alunos com deficiência. 2015 b.

BRASIL. Portaria SEDH n 2.344, de 3 de novembro de 2010. 2010.

CAMARGO, Eder Pires de; NARDI, Roberto. Panorama geral das dificuldades e viabilidades para a inclusão do aluno com deficiência visual em aulas de óptica. Revista de Educação em Ciência e Tecnologia, v. 1, n. 2, p. 81-106, 2008.

CAMARGO, Eder Pires de; NARDI, Roberto; VERASZTO, Estéfano Vizconde. Revista Brasileira de Ensino de Física, v. 30, n. 3, p. 3401-3413, 2008. DOI:

10.1590/S1806-11172008000300016.

CERQUEIRA, Jonir Bechara; FERREIRA, Elise de Melo Borba. Os recursos didáticos na educação especial. Revista Benjamin Constant, nº 5, p 24-29, 2000.

CHIAVENATO, Idalberto. Administração de recursos humanos: fundamentos básicos. 5. ed. São Paulo: Atlas, 2003.

COSTA, Olemar Silva da; CERQUEIRA Jonir Bechara. Técnicas de cálculo e didática do soroban método oriental maior valor relativo. Instituto Benjamin Constant, Rio de Janeiro, RJ, 2019.

COSTA, Alessandra Françoso da Silva; VINHOLI JÚNIOR, Airton José; GOBARA, Shirley Takeco. Ensino de biologia celular por meio de modelos concretos: um estudo de caso no contexto da deficiência visual. Revista Electrónica de Investigación en Educación en Ciencias, v. 14, n. 1, p. 50-64, 2019a.

COSTA, Ailton Barcelos da; GIL, Maria Stella Coutinho de Alcântara ELIAS, Nassim Chamel. Ensino de frações para adolescentes com deficiência visual. Ciência e Educação, v. 25, n. 4, p. 1047-1065, 2019b. DOI: 10.1590/1516-731320190040013

D'ABREU, João Vilhete Viegas; RAMOS, Josué J. G.; MIRISOLA, Luiz G. B., BERNARDI, Núbia. Robótica educativa/pedagógica na era digital. II Congresso Internacional TIC e Educação

RBPPD/BRJPD | Vol. 2 | n. 4 | p. 184-216, 2020. 
Simpósios a Snapshot of Digital Storytelling in European Formal and Informal Education. Anais ... Lisboa, Portugal, 2012.

DALLABRIDA, Adarzilse Mazzuco; LUNARDI, Geovana Mendonça. O acesso negado e a reiteração da dependência: a biblioteca e o seu papel no processo formativo de indivíduos cegos. Cadernos CEDES, v. 28, n. 75, p. 191-208, 2008. DOI: 10.1590/S0101-32622008000200004

DIAS, Camila Ehrat; PANOSSIAN, Maria Lucia. O ensino de Polinômios usando material acessível para alunos cegos: potencialidades e limitações. Revista de Educação Matemática, v. 15, n. 20, p. 409-431, 2018. DOI: 10.25090/remat25269062v15n202018p409a431

DOMINICI, Tânia P.; OLIVEIRA, Ednilson; SARRAF, Viviane; GUERRA, Fernanda Del. Atividades de observação e identificação do céu adaptadas às pessoas com deficiência visual. Revista Brasileira de Ensino de Física, v. 30, n. 4, p. 4501-4508, 2008.

DUARTE, Thiago Ribeiro. Configuração e suporte à impressão Braille: capacitação para produção de material didático para deficientes visuais. Dissertação (Mestre em Diversidade e Inclusão, Universidade Federal Fluminense, Niterói, RJ). 2017.

DUARTE, Thiago Ribeiro.; LIMA, Neuza Rejane Wille. Adaptação de livros didáticos para o Sistema Braille: uma proposta Inclusiva. In: LIMA, Neuza Rejane Wille e DELOU, Cristina Carvalho. Pontos de Vista em Diversidade e Inclusão, volume 2. ABDIn/PERSE, Niterói, RJ, 2016, Cap. 20. p. 147-149.

DUARTE, Thiago Ribeiro; TEDERIXE, Lisânia Cardoso; PINHO, Tânia Maria Moratelli; DELOU, Cristina Maria Carvalho; FERNANDES, Edicléia Macarenhas; LIMA, Neuza Rejane Wille. Braille material production for special education teachers. Creative Education, v. 11, n. 5, p. 652-673, 2020. DOI: 10.4236/ce.2020.115049653

EVANGELISTA, Fábio Lombardo. Materiais pedagógicos de baixo custo para o ensino de corrente elétrica para alunos com deficiência visual. Revista Educação, Artes e Inclusão, v. 1, n. 1, p. $1-12,2008$.

FARIA, Bianka Alves de; BONOMO, Fernanda Araújo França; RODRIGUES, Ana Clara Cândido, VARGAS; NOBRE, Gustavo; SILVA, João Paulo Barbosa; OLIVEIRA, Mislene da Silva Gomes; BENITE, Claudio Roberto Machado. Ensino de química para deficientes visuais numa perspectiva inclusiva: estudo sobre o ensino da distribuição eletrônica e identificação dos elementos químicos. In: XI Encontro Nacional de Pesquisa em Educação Em Ciências. Universidade Federal de Santa Catarina, Florianópolis, SC. ABRAPECTNET. 2017.

FERNANDES, Jomara Mendes; FRANCO-PATROCÍNIO; Sandra, Maria Helena ZAMBELLI; Ivoni de FREITAS-REI. A elaboração de materiais para o ensino de modelos atômicos e distribuição eletrônica para discente cego: produtos de um projeto PROBIC-J. Experiências em Ensino de Ciências, v. 12, n. 6, p. 95-108, 2017.

GÔNGORA, Francisco Carlos. Tendências Pedagógicas na Prática Escolar. Edições Loyola. São Paulo. 1985.

GRAYBILL, Cameala M.; SUPALO, Cary A.; MALLOUK, Thomas E.; AMOROSI, Christeallia; RANKEL, Lillian. Low-cost laboratory adaptations for precollege students who are blind or visually impaired. Journal of Chemical Education, v. 85, n. 2, p. 243-247, 2008. DOI: $10.1021 /$ ed085p243

HERZBERG, Frederick. Mais uma vez: como motivar seus funcionários. In: VROOM, Victor. Gestão de pessoas, não de pessoal. Rio de Janeiro: Campos dos Goytacazes, 1997. 
LOBOS, Julio. Teorias sobre a motivação no trabalho. Revista de Administração de Empresa, v. 15, n. 2, p. 17-25, 1975. DOI: 10.1590/S0034-75901975000200002

LUBART, Tood. Psicologia da criatividade. Ed. Artmed. 2009.

MACHADO, Thais. (Org.); NETO, Brasílio A; BENEDET, Josiane. (col.) Criatividade em sala de aula. 5. Ed.- Curitiba, PR: Humana Editorial, 2005.

MAMCASZ-VIGINHESKI; Lúcia Virginia, SHIMAZAKI; MIDORI, Elsa; SILVA, Sani de Carvalho Rutz da; PACHECO, Edilson Roberto. Formação de conceitos em geometria e álgebra por estudante com deficiência visual. Ciência e Educação, v. 23, n. 4, p. 867-879, 2017. DOI: $10.1590 / 1516-731320170040008$

MARRA; Nayara Nogueira Soares; CAMPOS, Regina Célia Passos Ribeiro de; SILVA, Nilma Soares da; CAVALCANTE, Fabiana Silva Zuttin. Atividade experimental de química para uma turma inclusiva com um estudante cego: a importância do estudo do contexto. Experiências em Ensino de Ciências, v. 12, n. 8, p. 14-30, 2017.

MARTÍNEZ, Albertina Mitjáns. Criatividade no trabalho pedagógico e criatividade na aprendizagem: uma relação necessária? In: Maria Carmen V. R. Tacca. (Org.). Aprendizagem e Trabalho Pedagógico. $1^{\mathrm{a}}$. ed., Campinas: Alínea, v. 1, p. 69-94, 2006.

MAXIMIANO, Antonio Cesar Amaru. Teoria geral da administração: da escola científica à competitividade na economia globalizada. 7. ed. São Paulo: Atlas, 2000.

MEC. MINISTÉRIO DA EDUCAÇÃO. Secretaria de Educação Especial. Saberes e práticas da inclusão estratégias para a educação de alunos com necessidades educacionais especiais. 2003.

MOREIRA, Andreia Aparecida Silva. Motivação nas organizações: situação motivacional em uma cooperativa de crédito à luz dos fatores higiênicos e motivacionais de Frederick Herzberg. Revista Científica Multidisciplinar Núcleo do Conhecimento, Ano 03, Ed. 09, v. 11, p. 147-172. DOI: 10.32749

MUKHERJEE, Anirban; GARAIN, Utpal; BISWAS, Arindam. Experimenting with automatic text-to-diagram conversion: a novel teaching aid for the blind people. Educational Technology and Society, v. 17, n. 3, p. 40-53, 2014.

NUEMBERG, Adriano Henrique. Contribuições de Vigotski para a educação de pessoas com deficiência visual. Psicologia em Estudo, v. 13, n. 2, p. 307-316, 2008. DOI:

10.1590/S1413-73722008000200013

OLIVEIRA, Edney Dantas de; SILVA, Heverton de Souza Bezerra da; SENA, Maria Helena Franco; VICTORIO, Marta Maria Donola; CAROPRESO, Regina Celia. Técnicas de cálculo e didática do soroban método ocidental menor valor relativo. Instituto Benjamin Constant, Rio de Janeiro, RJ, 2016.

PASSOS, Cármen Lúcia Brancaglion. Materiais manipuláveis como recursos didáticos na formação de professores de Matemática. In: LORENZATO, S. (org.). Coleção formação de professores, $3^{\mathrm{a}}$ ed. Campinas: Autores Associados, p. 76 -92, 2012.

PEDROSA, Letícia Leonardi; GUIMARÃES, Orliney M. Os materiais didáticos adaptados para deficientes visuais nas aulas de Química na perspectiva de alunos cegos, especialista e gestor educacional. XVIII Encontro Nacional de Ensino de Química, Florianópolis, SC. Florianópolis, Anais ... 2016. 
PERDIGÃO, Luciana Tavares; LIMA, Neuza Rejane Wille. Imagens que falam: a áudio-descrição em materiais didáticos. Cap. 6. p. 56-61. In: LIMA, Neuza Rejane Wille e DELOU, Cristina Carvalho. Pontos de Vista em Diversidade e Inclusão, volume 2. ABDIn/PERSE, Niterói, RJ, 2016.

PINHO, Tânia Maria Moratelli. A adaptação de materiais pedagógicos para o ensino de matemática para estudantes com deficiência visual $\left(6^{\circ}\right.$ ao $9^{\circ}$ ano) do ensino fundamental. Dissertação (Mestre em Diversidade e Inclusão, Universidade Federal Fluminense, Niterói, RJ). 2016.

PINHO, Tania Maria Moratelli; CASTRO, H. C.; ALVES Leonardo; LIMA, Neuza Rejane Wille. Mathematics and blindness: let's try to solve this problem? Scholedge International Journal of Multidisciplinary \& Allied Studies, v. 3, n. 10, p. 215-225, 2016a. DOI:

10.19085/journal.sijmas031002

PINHO, Tania Maria Moratelli, DELOU, Cristina Maria Carvalho, LIMA, Neuza Rejane Wille. Origami as a tool to teach geometry for blind students. Creative Education, v. 7, n. 17, p. 2652-2665, 2016b. DOI: 10.4236/ce.2016.717249

PINHO, Tânia Maria Moratelli; LIMA, Neuza Rejane Wille. Dobraduras e colagens no ensino de Geometria para estudantes cegos do Ensino Fundamental no período de contraturno. Ensino e Pesquisa, v. 15, n. 4, p. 237-253, 2017a.

PINHO, Tânia Maria Moratelli; LIMA, Neuza Rejane Wille. O uso da música em uma oficina de geometria para alunos cegos do ensino fundamental. In: LIMA, Neuza Rejane Wille, DELOU, Crisitina Maria Carvalho e PERDIGÃO, Luciana Tavares (Org.). Pontos de vista em diversidade e inclusão, v. 3, ABDIn/PERSE, Niterói, RJ, 2017b, p. 146-154.

PONTES, Ana Claudia Nunes; FERNANDES, Edicléa Mascarenhas. O uso de recursos didáticos adaptados na escolarização e inclusão de educandos cegos e de baixa visão. p. 1-21. IV Colóquio Luso-Brasileiro de Educação. Currículo Inclusão e II Educação Escolar, Anais ... Braga e Paredes de Coura, Portugal, 2018.

QUTIESHAT, Abubaker; AOUIDIDI, Rayhana; ARFAOUI, Rayan. Design and construction of a low-cost arduino-based $\mathrm{pH}$ sensor for the visually impaired using universal $\mathrm{pH}$ paper. Journal of Chemical Education, v. 96, p. 2333-2338, 2019. DOI: 10.1021/acs.jchemed.9b00450

RAMOS, Josué J. G.; MIRISOLA, Luiz G. B.; BERNARDI, Núbia. Robótica educativa/pedagógica na era digital. In: II Congresso Internacional TIC e Educação. Instituto de Educação da Universidade de Lisboa, Anais ... Lisboa, Portugal, p. 2449-2465, 2013.

RASLAN FILHO, Gilson Soares; BARROS, Janaina Visibeli. Creativity in School: emancipation or instrumentalization? Educação e Realidade, v. 43, n. 4, p. 1499-1514, 2018. DOI: $10.1590 / 2175-623675477$.

RIBEIRO, Olzeni Costa; MORAES, Maria Cândida. Criatividade em uma perspectiva transdisciplinar: rompendo crenças, mitos e concepções. UNESCP Digital Books. 2014.

ROSAS, Argentina. Estimulação e desenvolvimento da criatividade Psicologia. Ciência e Profissão, v. 12, n.1, p. 29-33, 1992. DOI: 10.1590/S1414-98931992000100006

SÁ, Elizabet Dias de; CAMPOS, Izilda Maria de; SILVA, Myriam Beatriz Campolina. Formação Continuada à Distância de Professores para o Atendimento Educacional Especializado em Deficiência Visual. SEESP/SEED/MEC, Brasília/DF, v. 33, 19-20, Editora Cromos, Curitiba, PR, 2007. 
SAKS, Flávia do Canto. Busca booleana: teoria e prática. Conclusão de Curso apresentado à disciplina Pesquisa em Informação II do Curso de Gestão da Informação, Setor de Ciências Sociais Aplicadas, Universidade Federal do Paraná. 2005.

SANTOS, Jamille Ferreira Lima; BRITO, Marcelo Fulgêncio Guedes de. Educação inclusiva: modelo didático de peixe para alunos com deficiência visual no ensino de ciências e biologia. Revista Ciências e Ideias, v. 10, n. 3, p. 206-223, 2014. DOI:

10.22047/2176-1477/2019.v10i3.1022

SILVA, Alexandre Chaves da; SANTOS, Carlos Alberto dos. Lâminas em alto-relevo para ensinar fenômenos ondulatórios a deficientes visuais. Revista Brasileira de Ensino Física, v. 40, n. 4, e5406, 2018. DOI: 10.1590/1806-9126-RBEF-2018-0089

SILVA, Mayra Darly da; CARVALHO, Liliane Maria Teixeira Lima de; PESSOA, Cristiane Azevêdo dos Santos. Material manipulável de geometria para estudantes cegos: reflexões de professores brailistas. Revista Paranaense de Educação Matemática, v. 5, n. 9, p. 176-202, 2016.

SILVA, Tiago Stefanelo; LAZZARIN, João Roberto. Matemática Inclusiva: Ensinando matrizes a deficientes visuais. Ciência e Natura, v. 39 n. 1, p. 118- 126. 2017. DOI: 10.5902/2179460X23408

SOARES, Karla Diamantina de Araújo; CASTRO, Helena Carla; DELOU, Cristina Maria Carvalho. Astronomia para deficientes visuais: Inovando em materiais didáticos acessíveis.

Revista Electrónica de Enseñanza de las Ciencias, v. 14, n. 3, p. 377-391, 2015.

SOUZA, Cristina Silva Ribeiro de. Livro tátil tridimensional de itinerância domiciliar para ensino de crianças cegas: um caminho lúdico na promoção da saúde. Dissertação (Mestre em Diversidade e Inclusão, Universidade Federal Fluminense, Niterói, RJ). 2019.

SOUZA, Cristina Silva Ribeiro de; DIAS, Rafaela Rego Rivetti; LIMA, Daniel de Castro Franco; TEDERIXE, Lisânia Cardoso; CASTRO, Helena Carla; LIMA, Neuza Rejane Wille.

Sensibilizando futuros docentes para uma prática pedagógica inclusiva através da construção de um livro tátil: uma reflexão necessária. Experiências em Ensino de Ciências, v. 14, n. 3, p. 58 -71, 2019.

SOUZA, Cristina Silva Ribeiro de; TEDERIXE, Lisânia Cardoso; DE CICCO, Nuccia Nicole Theodoro; CASTRO, Carla Castro; LIMA, Neuza Rejane Wille. Educational practices for oral health promotion of blind students using three-dimensional tactile book. Creative Education, v. 11, n. 3, p. 220-228, 2020. DOI: 10.4236/ce.2020.113016

SPOSITO, Marilia Pontes. Celso de Rui Beisiegel: o legado de um intelectual em defesa da educação popular pública. Educação e Pesquisa, v. 44, e1040-1100, 2018. DOI:

$10.1590 / \mathrm{s} 1678-463420184410401100$

STERNBERG, Robert J. The Nature of Creativity. Creativity Research Journal, v. 18, n. 1, p. 87-98, 2006.

TEDERIXE, Lisânia Cardoso. Livro tátil: as possibilidades de ensino e aprendizado da criança cega. Dissertação (Mestre em Diversidade e Inclusão, Universidade Federal Fluminense, Niterói, RJ). 2019.

TEDERIXE, Lisânia Cardoso; LIMA, Neuza Rejane Wille. Livro tátil: um recurso no aprendizado do aluno com deficiência visual. V Colóquio Internacional Educação, Cidadania e Exclusão, Universidade Federal Fluminense, Niterói - RJ, Anais ... p. 1-4, 2018.

TORRE, Saturnino de la. Dialogando com a criatividade. Trad. Cristina Mendes Rodriguez. Editora Madras. São Paulo, 2005. 
ULIANA, Marcia Rosa. Inclusão de estudantes cegos nas aulas de matemática: a construção de um kit pedagógico. Bolema, v. 27, n. 46, p. 597-612, 2013. DOI: 10.1590/S0103-636X2013000300017

UNESCO. Declaração de Salamanca sobre princípios, políticas e práticas na área das necessidades educativas especiais e estrutura de ação em educação especial. Salamanca, 1994.

VINTER, Annie; ORLANDI, Oriana; MORGAN, Pascal. Identification of textured tactile pictures in visually impaired and blindfolded sighted children. Frontier in Psychology, v. 11, p. 1-13, 2020. DOI: : $10.3389 /$ fpsyg.2020.00345

VITORIANO, Felipe A., TELES, Vânia L. G.; RIZZATTI, Ivanise M.; LIMA, Régia C. Pessoa de. Promoting Inclusive Chemistry Teaching by Developing an Accessible Thermometer for Students with Visual Disabilities. Journal of Chemistry Education, v. 93, n. 12, p. 2046-2051, 2016. DOI: $10.1021 /$ acs.jchemed.6b00162

WERLANG, Jorge Daniel; BIANCHI, Márcia; VENDRUSCOLO, Maria Ivanice. Estudo dos fatores extrínsecos e intrínsecos que motivam os discentes na escolha e na permanência no curso de Ciências Contábeis da Universidade Federal do Rio Grande do Sul (UFRGS). Congresso de Contabilidade, 2015. Anais ... Universidade Federal de Santa Catarina, Florianópolis, SC. p. 1-17, 2015. 